\title{
Interactions between Segmental Homologs and between Isoneuronal Branches Guide the Formation of Sensory Terminal Fields
}

\author{
Wen-Biao Gan and Eduardo R. Macagno \\ Department of Biological Sciences, Columbia University, New York, New York 10027
}

\begin{abstract}
Process outgrowth and peripheral field innervation by an identified mechanosensory neuron were examined in the intact embryonic leech. The dorsal pressure-sensitive $\left(P_{D}\right)$ neurons of the leech CNS are found as bilateral pairs in every segmental ganglion, and are amenable to study at early ages in intact embryos. Each $P_{D}$ has one major axonal projection that putatively pioneers the nerve to the dorsal body wall and branches extensively in its own segment, and two minor projections that innervate, via neighboring ganglia, smaller areas in adjacent segments. We found that adjacent embryonic $P_{D}$ cells form overlapping terminal fields in the body wall, but that the extent of overlap was governed by inhibitory interactions among these fields. When one $P_{D}$ neuron was ablated, the adjacent $P_{D}$ cell changed its peripheral arborization by (1) its major axon producing more filopodia and extending longer side branches toward the ablated cell and (2) its minor axon producing a larger arbor in the operated segment. Interestingly, although growth was biased toward the side of the ablated neuron, reduced outgrowth of the $P_{D}$ cell was found on the side away from the ablation, while the total extent of arborization of the $P_{D}$ cell kept relatively constant. Further, we found that axotomy of the major $P_{D}$ projection resulted in extensive outgrowth of its minor projections. These results suggest that a single $P_{\mathrm{D}}$ neuron has a limited capacity for growth, each of its branches growing at the expense of the others, and that inhibitory interactions between neighboring $P_{D}$ neurons influence the extent and direction of that growth.
\end{abstract}

[Key words: pathfinding, growth cones, development, contact inhibition, CNS, leech, cell-cell interactions, guidance, sibling neurite bias, axotomy, Hirudo medicinalis]

Neuronal growth cones use a variety of guidance cues to lead axons toward their targets (Lumsden and Davies, 1986; Westerfield et al., 1986; Walter et al., 1987; Landmesser et al., 1990; Halpern et al., 1991). Once near the target, axons arborize extensively, beginning a process that culminates in the formation

\footnotetext{
Received Aug. 8, 1994; revised Nov. 22, 1994; accepted Nov. 29, 1994

We thank Dr. Laura Wolszon for her critical reading of the manuscript, and Dr. Mu-Ming Poo and Michael Nitabach for useful comments. We also thank Nik Necles for assistance with photographic work. This work was supported by grants from the National Science Foundation and the National Institutes of Health.

Correspondence should be addressed to Eduardo R. Macagno, Columbia University, Department of Biological Sciences, 1003 Fairchild Building, New York, NY 10027.

Copyright $\odot 1995$ Society for Neuroscience $0270-6474 / 95 / 153243-11 \$ 05.00 / 0$
}

of terminal fields. This process is not well understood, but experimental evidence in several systems suggests that, besides interactions with the target, interactions among axonal terminals of different cells and between different branches of the same neuron are important.

Competitive interactions among axonal terminals of different neurons aid in the refinement of terminal arborizations, as has been shown in developing and regenerating nervous systems (reviewed in Lnenicka and Murphey, 1989; Goodman and Shatz, 1993). A classic example is found in the mammalian visual cortex, where ocular dominance columns changc form when one eye is enucleated or sutured shut during a critical period (e.g., Hubel et al., 1977). Similarly, the retinotectal projections in the goldfish (e.g., Schmidt et al., 1978) and the sensory terminals in the skin of salamander or adult rat (Diamond et al., 1976; Jackson and Diamond, 1981) expand their innervation fields after denervation of adjacent areas. In leeches, ablations of adult $\mathrm{T}$ or $\mathrm{N}$ mechanosensory neurons (Blackshaw et al., 1982) or embryonic AE motor neurons (Gao and Macagno, 1987b) cause the remaining homologs to expand their territories. Although the underlying mechanisms are generally unknown, neuronal activity and target-derived growth-promoting factors may be involved in competitive interactions (e.g., Thompson, 1983; Cline and Constantine-Paton, 1989; Shatz, 1990; Diamond et al., 1992).

The outgrowth of a particular branch can also be affected by the growth of other branches of the same neuron. Devor and Schneider (1975) have proposed that the total axonal arborization of an individual neuron is self-regulated. A possible explanation for this idea is that different axonal branches of a neuron compete for a limited supply of materials generated by its synthetic machinery. This phenomenon, that some neurites grow at the expense of others, has been called "sibling neurite bias" by Smalheiser and Crain (1984). An interesting corollary is that environmental cues, by modulating the outgrowth of the neurites that encounter them, can also affect indirectly the outgrowth of other, distant neurites of the same cell. Several studies have provided evidence in support of these ideas (e.g., Devor and Schneider, 1975; Frost and Schneider, 1979; Goldberg and Schacher, 1987), particularly the study of sensory neuron development in the cricket by Murphey and Lemere (1984). When they removed one of the two cerci, Murphey and Lemere found that an individual sensory neuron on the intact cercus shifted its distribution of varicosities within the terminal field while maintaining a nearly constant total number of varicosities. The interpretation of this result, however, was complicated by the fact that many neurons, including postsynaptic targets of the sensory neuron, were 
affected by the removal of the cercus, making it difficult to assign the result exclusively to sibling neurite bias.

We examined terminal field formation by a leech mechanosensory neuron, the dorsal pressure-sensitive $\left(\mathrm{P}_{\mathrm{D}}\right)$ cell of Hirudo medicinalis. These neurons are found as bilateral pairs in each body segment and have been shown to be the first central neurons to grow to the developing dorsal body wall in a different leech species Haementaria ghilianii (Kuwada and Kramer, 1983; Kuwada, 1985). We found that interactions between adjacent segmental homologs, combined with compctition among branches of a single cell, regulate the pattern and size of a $P_{D}$ cell's sensory field. In addition to elucidating some of the cellular processes involved in the establishment of mechanosensory fields, these studies provide direct evidence in support of the "sibling neurite bias" hypothesis.

\section{Materials and Methods}

Animals. Hirudo medicinalis embryos were obtained from our laboratory colony, maintained at $23^{\circ} \mathrm{C}$. We used the same criteria to stage embryos as described earlier by Fernandez and Stent (1982).

Cell ablations. Cell kills were carried out as in Gao (1989). Embryos were anesthetized with 9\% ethanol in sterile, dilute Instant Ocean (Menasha Corporation; $0.5 \mathrm{gm} / \mathrm{liter}$ ) and were positioned in a groove cut into a Sylgard-coated (Dow Corning) microslide. The anterior and posterior regions of the embryos were covered with slender pieces of cover glass to prevent movement. For embryos older than E9, a small patch of skin was cut over the experimental ganglion to identify the $P_{D}$ cells, which were then penetrated by microclectrodes. For cmbryos younger than E9, electrodes could penetrate the skin easily without dissection.

Glass microelectrodes with resistances of about $100 \mathrm{M} \Omega$ were pulled on a Sutter model P-87 puller, and the tips were then bent to approximately 45 degrees, relative to the electrode shafts, to accommodate the working distance of the $40 \times$ water-immersion objective. $P_{D}$ cells were impaled with electrodes filled with 1\% 5(6)-carboxyfluorescein (Sigma) in $0.2 \mathrm{M} \mathrm{KCl}$. The dye was iontophoresed using negative pulses (1 $\mathrm{nA}$, $1 \mathrm{~Hz}$ for $3 \mathrm{~min}$ ).

$P_{D}$ cells within midbody ganglia MG10-18 were used for the ablation experiments described here. The injected $P_{D}$ cells and parts of their branches were illuminated with a xenon-arc lamp for 1 min. Dying cells were indicated by having a swollen soma and beaded structures along their axons. Death ensued within $1 \mathrm{~d}$. After photoablation, the embryos were allowed to recover in stcrile Instant Ocean and continued to de velop normally.

Cutting the roots. The anesthetized embryos were first positioned in a groove cut as described above. A small patch of skin was then cut lo expose the experimental ganglion. The roots were cut with a sharp pin. After surgery, the embryos were returned to sterile Instant Ocean.

Labeling neurons with DiI and DiO. The embryos were first cut along the dorsal midline to remove the yolk and were then anesthetized with $9 \%$ ethanol in Wenning's solution (Wenning, 1987; $40 \mathrm{~mm}$ DL-malic acid, $4 \mathrm{~mm} \mathrm{KCl}, 10 \mathrm{~mm}$ succinic acid, $10 \mathrm{~mm}$ tris- $\mathrm{HCl}, 1.8 \mathrm{~mm} \mathrm{CaCl}_{2}$ $\mathrm{pH}$ 7.4). They were then pinned to a Sylgard dish, and the ventral midline was cut with fine forceps and scissors to expose the ganglia

Electrodes $(100 \mathrm{M} \Omega)$ were filled with a $1 \%$ solution of $1,1^{\prime}$-dioctadecyl-3,3,3',3'-tetramethylindocarbocyanine perchlorate (DiI, Molecular Probes) or 3,3'-dioctadecyloxacarbocyanine perchlorate (DiO, Molecular Probes) in $100 \%$ methylene chloride (Sigma). Under the $40 \times$ waterimmersion objective, the soma was impaled and a depolarizing current ( $1 \mathrm{nA}, 1 \mathrm{~Hz}$ ) was applied for a few seconds until a small crystal was formed at the tip of the electrode. The electrode was then removed, the Dil crystal remaining inside the cell body. For double staining, another neuron was similarly stained with $\mathrm{DiO}$.

Imaging the preparation. After staining, preparations were fixed for 2-7 d at room temperature in $4 \%$ paraformaldehyde, depending on the age of the embryos, to allow the dyes to diffuse to the fine processes. The preparation was then immersed in $100 \%$ glycerol and mounted. Images were taken with a confocal microscope (Bio-Rad, MRC-600) by optically sectioning the embryo, so that neuronal processes at different focal planes were imaged. The optical sections were then superimposed to generate the final images.

Quantification of the outgrowth of the $P_{D}$ cell. Two different methods were used to quantitate the amount of growth of the $P_{D}$ cell. In the first method, we took advantage of the regular growth pattern of the major projections of the $P_{D}$ cell. After E11, the major projection of the $P_{D}$ cell has six first-order branches approximately perpendicular to the main projection (see Fig. 1A). The Indjor projection extends along the middle annulus of the five that make up a segment, and the first-order branches extend about three to four annuli anteriorly and posteriorly, into the adjacent segments. Higher order branches emanate along these first branches, with approximately the same amount of arborization around the center of each annulus, except in the distal annuli where the $P_{D}$ cell usually has fewer higher order branches. Thus, the amount of growth of each of the six first-order branches is approximately proportional to the length of the branch, which we measured in units of annular width. Such a method of measurement has the advantage that it also normalizes for possible variations in the stretching of the preparation during dissection and fixation.

We used a second method of quantification to check the reliability of the method just described. In this case, a transparent square grid (squares with sides corresponding to about $G \mu \mathrm{m}$ ) was placed on micrographs of dye-filled $P_{D}$ cells, covering the full region innervated by the cell. To estimate the amount of outgrowth of any branch, we counted those squares containing any part of the arbor and normalized to the total number of squares covering the body wall (lateral midline to dorsal midline, innervated annuli). We used this method to quantitate, in six preparations, the total amount of outgrowth of the major projection on the side of ablation versus the side away from ablation. The two methods gave very consistent results.

\section{Results}

Embryonic $P_{D}$ cells establish unequal peripheral arbors in three adjacent segments

In the embryo of Haementaria ghilianii, a leech from a different order than the species used in our experiments, the $P_{D}$ cells are the first central neurons to extend axonal projections to the dorsal region of the body wall, apparently establishing the dorsal posterior (DP) nerves (Kramer and Kuwada, 1983; Kuwada and Kramer, 1983; Kuwada, 1985). Although we did not directly assess whether the $P_{D}$ cell is the first cell to reach the dorsal body wall, we did observe a very similar pattern of growth of the $\mathrm{P}_{\mathrm{D}}$ cell in Hirudo medicinalis (Fig. 1A). On embryonic day 7 (E7), each $P_{D}$ cell in midbody ganglia MG10-MG18 extended one major projection directly to the periphery and two minor projections in the connective nerves that eventually reached the periphery via the adjacent ganglia. In the periphery, both major and minor projections traveled along the middle annulus of the five that comprise a segment in the Hirudo midbody (segments contain fewer annuli at the head and tail). The growth cone of the major projection reached the edge of the germinal plate in its own segment at E8. Minor projections in adjacent segments followed major projections of the local $\mathrm{P}_{\mathrm{D}}$ cell closely, and their growth cones also reached the edge of the germinal plate at approximately E8 (Fig. 1B). Interestingly, major projections had many filopodia along their shafts, as well as at the growth cone itself, whereas minor projections had many fewer filopodia.

Three anterior and three posterior first-order branches emerged approximately perpendicular to the major projection once it reached the dorsal germinal plate (Fig. $1 C$ ). Many filopodia were seen along these branches from E8 to E9, some forming second-, third-, and fourth-order branches during the period from E9 to E14. The resulting arbor covered approximately six to seven annuli arraycd symmetrically about the central annulus (Fig. $1 D$ ), whereas arbors of the minor projections covered, at most, two annuli. The territory innervated by the $P_{D}$ cell at E12 was not significantly different in terms of numbers of annuli, from those at E14 or in the adult (Nicholls and Baylor, 1968), suggesting that the general morphology of the $P_{D}$ cell does not change after E14. Although the peripheral arbor of the 

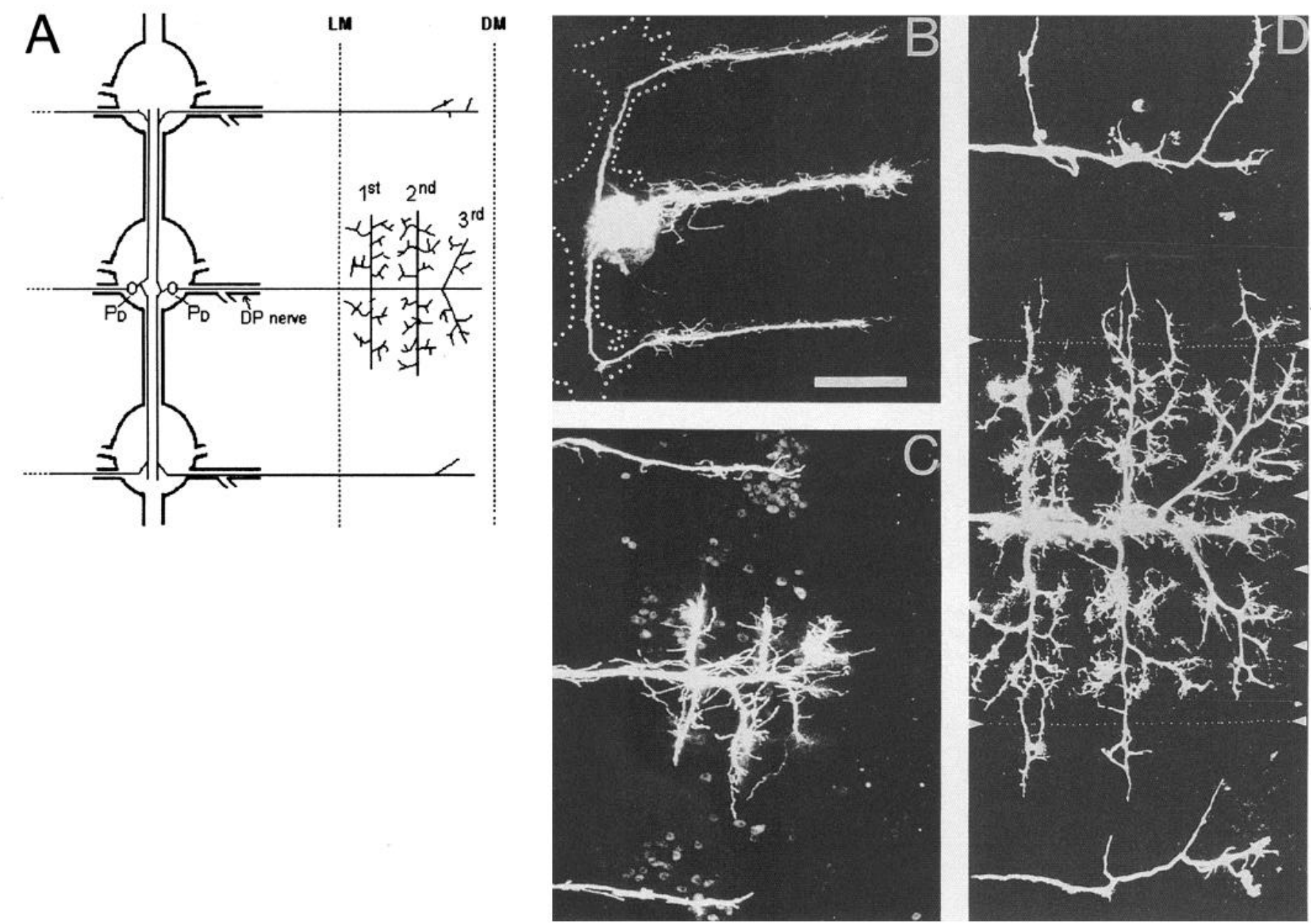

Figure 1. Outgrowth of the pioneer $\mathrm{P}_{\mathrm{D}}$ cell in the periphery at different stages. $A$, Drawing of three adjacent segmental ganglia and of two $\mathrm{P}_{\mathrm{D}}$ cells at approximately E10. Each $P_{D}$ neuron sends a major axon through the dorsal posterior (DP) nerve of its own ganglion to dorsal skin, where it branches profusely, and two minor axons to the periphery of the adjacent segments through neighboring ganglia. The mirror-image branching pattern of the contralateral homolog is not shown, but was used as a control for several of the experiments described here. $L M$, lateral midline; $D M$, dorsal midline. Anterior is up in all panels. $B, \mathrm{P}_{\mathrm{D}}$ cell at E8. The major projection, presumably pioneering the DP nerve, reaches the edge of the dorsal germinal plate. Dotted lines depict the outline of the ganglia and the connective nerve. The two minor projections reach the corresponding position in adjacent segments via the connective nerves that link neighboring ganglia. $C, \mathrm{P}_{\mathrm{D}}$ cell at E9. The major projection forms six primary branches at this time, while the minor projections are devoid of branches. D, $\mathrm{P}_{\mathrm{D}}$ cell at E11. Dotted lines with arrowheads represent the segmental borders. The arrowheads on right margin indicate the borders of the five annuli of the central segment. The major axon has arborized extensively within each annulus, covering seven to nine annuli. Scale bar (in $B$ ), $100 \mu \mathrm{m}$ for $B-D$.

$P_{D}$ neuron continued to grow after E14, this further growth is not be described here.

Branches of the $P_{D}$ cells from adjacent segments were first seen to overlap with each other at E10 (Fig. 2A; one cell in red, the other in green; overlap in yellow) as they grew within the body wall. By E12-13, this overlap was about the length of two annuli (Fig. $2 B$ ). When optically sectioned using the confocal microscope, the apposed branches were always found to be in the same focal plane (not shown), suggesting close contact between two overlapping branches. Evidence that this apposition might mediate growth-inhibitory interactions is provided below.

\section{Adjacent $P_{D}$ homologs inhibit each other's outgrowth in the periphery}

To determine whether adjacent $P_{D}$ cells influence each others' peripheral growth, we ablated a $\mathrm{P}_{\mathrm{D}}$ cell at E8, when its major axon was just beginning to form first-order branches. The $P_{D}$ cells in adjacent ganglia were then stained with DiI to examine their outgrowth three to $6 \mathrm{~d}$ after ablation. The contralateral $\mathrm{P}_{\mathrm{D}}$ cells served as controls.

We found that the major and minor projections of adjacent $P_{D}$ cells expanded their arborizations into vacated territory when either the anterior or posterior homolog was deleted. In Figure $3, A$ and $B$ show that on the side of ablation, the area innervated by the three first-order branches of the major projection was larger than controls. We saw this effect as early as $3 \mathrm{~d}$ after ablation and continued to observe it up to E14; the oldest stage we examined in these experiments. Aided by the regular growth pattern of the $P_{D}$ cell's neurites, we were able to quantify the amount of branch outgrowth by measuring the numbers of annuli innervated by each branch. In the case of the second branch, for example, the number of annuli it innervated increased from a control value of $3.2 \pm 0.1$ (mean \pm SEM) annuli to an experimental value of $4.1 \pm 0.1$ annuli $4 \mathrm{~d}$ after ablation of the adjacent $\mathrm{P}_{\mathrm{D}}$ cell $(n=31 ; p<0.0001)$ (Fig. $\left.4 A\right)$. In addition, the minor projections also showed larger arbors than controls, 

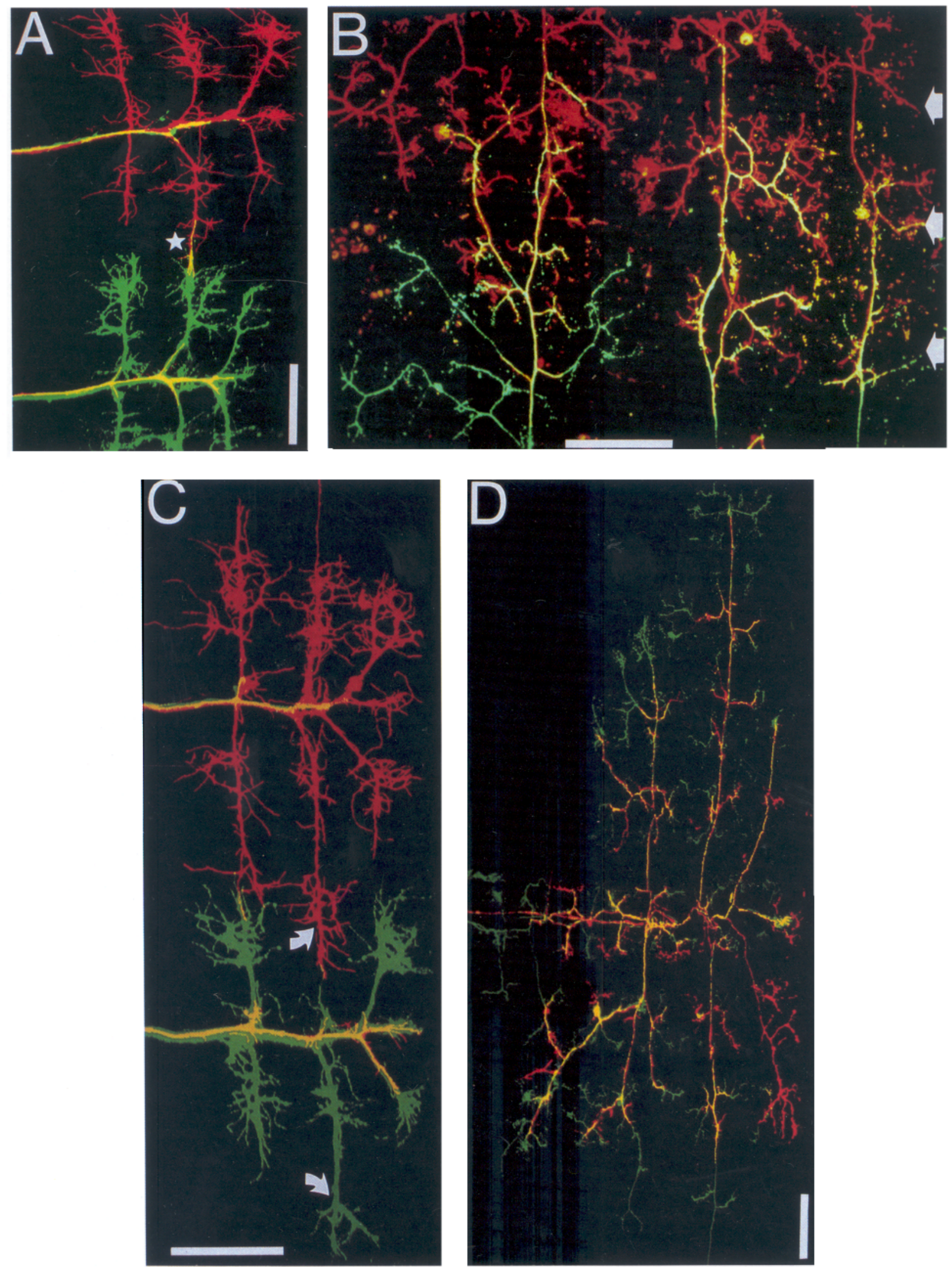

Figure 2. $A$ and $B$, Sites of contact between two adjacent $\mathrm{P}_{\mathrm{D}}$ cells in the dorsal germinal plate. Adjacent $\mathrm{P}_{\mathrm{D}}$ cells were labeled with DiI and DiO (red and green; regions of overlap are in yellow). Dorsal to the right, anterior is up. A, $\mathrm{P}_{\mathrm{D}}$ cell at E10, when the primary branches begin to overlap. The region of overlap between the growth cones of two branches is indicated by a star. The double staining also reveals that a minor projection of one $\mathrm{P}_{\mathrm{D}}$ cell follows faithfully the major projection of the other. $B, \mathrm{P}_{\mathrm{D}}$ cell at E12-13. Extensive overlap can be seen at this stage. $C$, Possible inhibitory interactions between adjacent $P_{D}$ cells are sometimes apparent during normal development. The two $P_{D}$ cells here were stained at E10. Note that the second anterior branch of the green cell failed to grow and that the vacant territory was innervated by the second posterior branch 

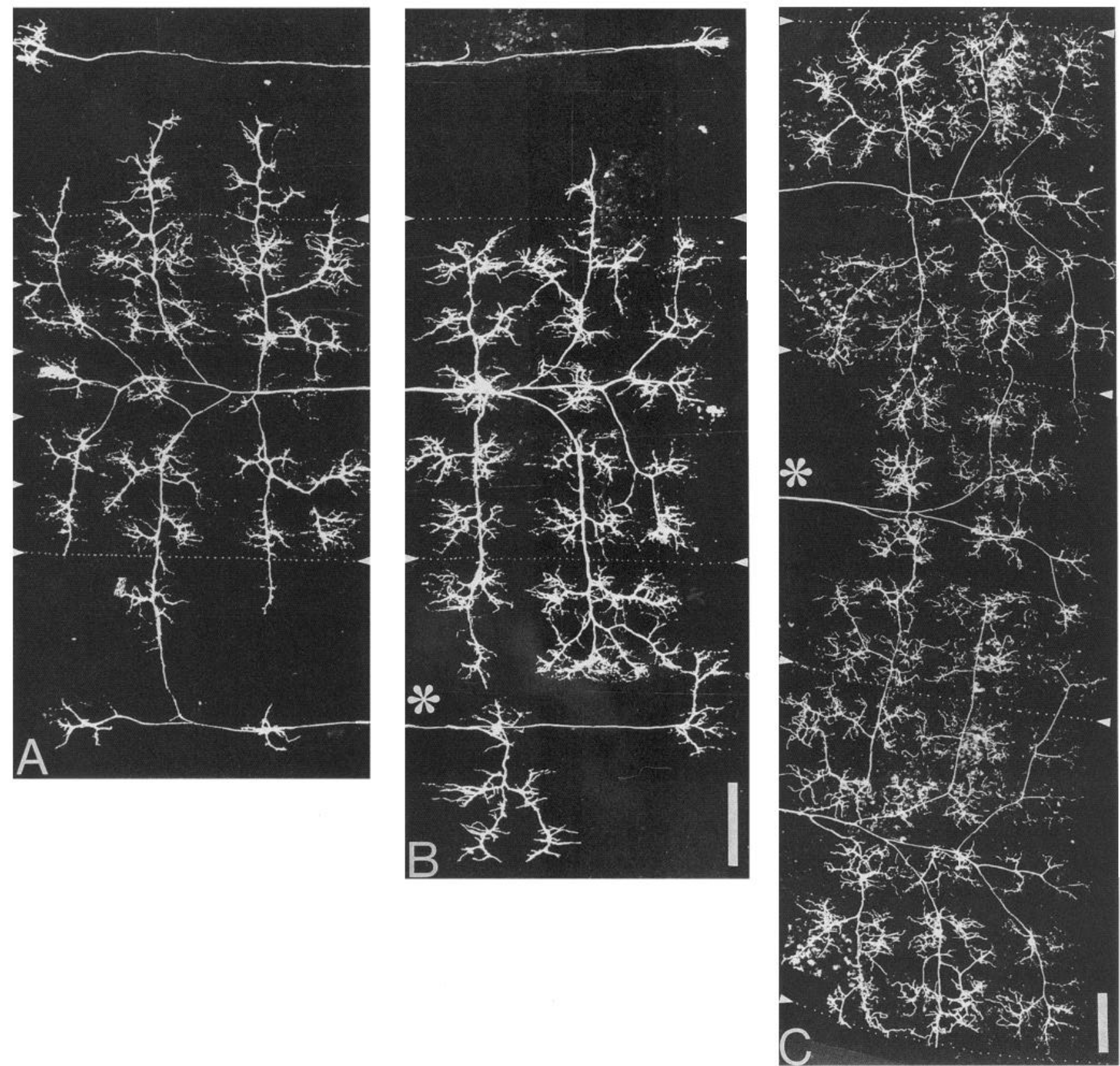

Figure 3. Ablation of a $\mathrm{P}_{\mathrm{D}}$ cell at E8 removes its inhibitory influence. $A$, The control $\mathrm{P}_{\mathrm{D}}$ cell for the experiment shown in $B$, illustrating normal growth. As in Figure $1 D$, adjacent arrowheads on the left side of the figure indicate the boundaries of annuli. $B$, The outgrowth of a $\mathrm{P}_{\mathrm{D}}$ cell $4 \mathrm{~d}$ after ablating its posterior homolog (ablation marked by asterisk). More outgrowth of its major and minor projections can be seen in the posterior territory (compare with control in A). C, Five days after ablation of the $\mathrm{P}_{\mathrm{D}}$ cell in the middle segment at E8 (site marked by asterisk), vacated territory is completely innervated by major and minor projections of the two adjacent $\mathrm{P}_{\mathrm{D}}$ homologs. Dotted lines and arrowheads represent the segmental borders. Scale bars, $100 \mu \mathrm{m}$ (bar in $B$ also for $A$ ).

3-6 d after ablation (compare Fig. 3A,B). The total number of annuli innervated by the minor projection increased from a control value of $0.9 \pm 0.1$ annuli to an experimental value of 2.8 \pm 0.3 annuli $(n=75 ; p<0.0001)$. Figure $3 C$ illustrates that the expanded outgrowth of the major and minor arbors of the two adjacent homologs eventually encompassed the entire territory vacated by an ablated $P_{D}$ cell. Taken together, these results support the hypothesis that $\mathrm{P}_{\mathrm{D}}$ cell outgrowth is normally inhibited by interactions with its adjacent homologs.

The inhibitory interactions between adjacent $P_{D}$ cells can

$\leftarrow$

of the red cell (upper arrow). Moreover, the corresponding second posterior branch of the green cell grew abnormally larger (lower arrow), as if to compensate for the short anterior branch. $D$, Expansion of minor arbors can occur in the presence of the neighboring $\mathrm{P}_{\mathrm{D}}$ cell. The induced growth of a $\mathrm{P}_{\mathrm{D}}$ 's minor projection (red) in the presence of the major projection (green) of the local $\mathrm{P}_{\mathrm{D}}, 4 \mathrm{~d}$ after manipulation (see text and diagram, Fig. $5 B)$. Scale bars, $100 \mu \mathrm{m}$. 


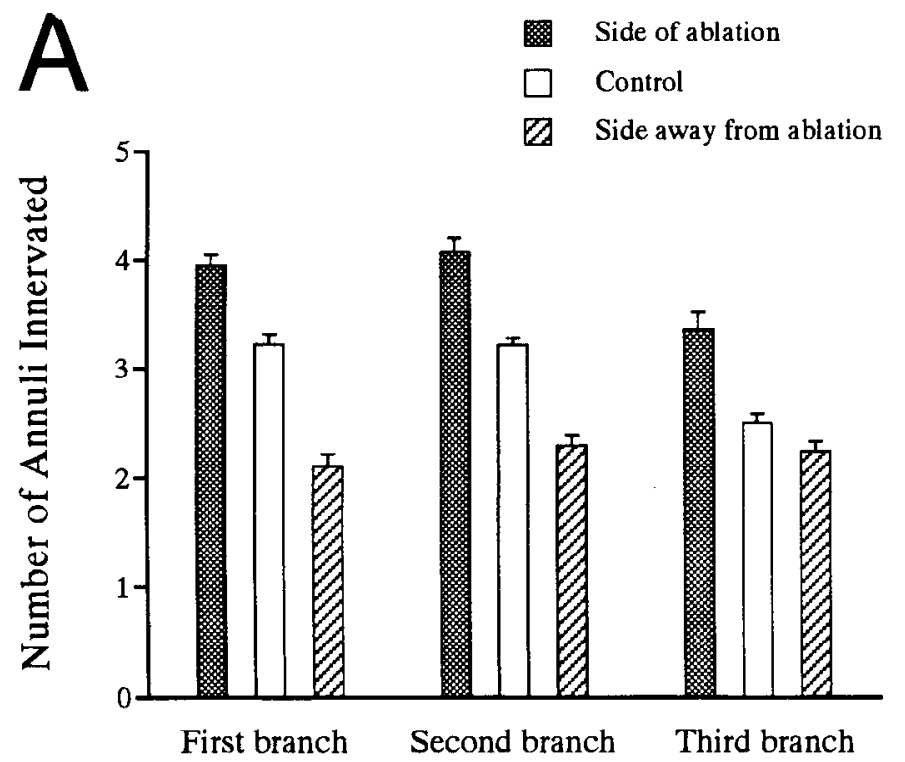

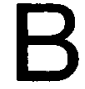

Ablation of anterior $\mathrm{P}$ cell

Control

Ablation of posterior $P$ cell

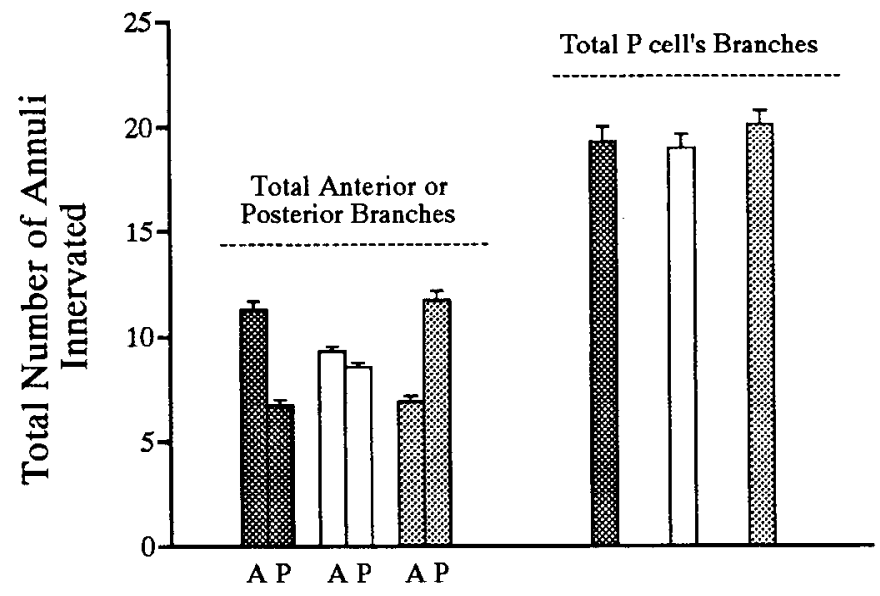

Figure 4. A, Data showing increased and reduced outgrowth of the $\mathrm{P}_{\mathrm{D}}$ major projection $4 \mathrm{~d}$ after ablation of an adjacent $\mathrm{P}_{\mathrm{D}}$ cell at E8. Compared with controls, ablation results in a signiticant increase in outgrowth of all three primary branches of the $P_{D}$ cell towards the ablation side, irrespective of whether towards anterior or posterior $(n=31$ for first and second branches, $n=29$ for third branches; $p<0.0001)$. Concomitant with the increased growth on the side of ablation, there is less growth of the branches on the side away from the ablation ( $n=31$ for first and second branches, $p<0.0001 ; n=28$ for third branches, $p<0.05$ ). $B$ (left), the number of annuli innervated by the three primary branches in each direction $(A=$ anterior branches, $P=$ posterior branches) were compared for control cells $(n=12)$ and those that had their anterior $(n=12, p$ $<0.005)$ or posterior $(n=12, p<0.001)$ ahlated. Note that when growth in one direction increased, that in the opposite direction decreased. Right, Data summed to illustrate the conservation of total cell outgrowth ( $n=12$ for either anterior or posterior ablated or control; $p>0.2)$. The outgrowth of the $P_{D}$ major and minor projections is quantified in terms of the number of annuli innervated; error bars represent SEM.

sometimes be seen even in unoperated embryos. An example is shown in Figure $2 C$, in which two adjacent $P_{D}$ cells were stained at E10. The unusually short second anterior branch of the green $P_{D}$ cell appeared to be compensated for by increased growth in the second posterior branch of the red cell.

\section{Some $P_{D}$ branches grow at the expense of others}

Compensatory reduction of outgrowth on the side opposite to the ablation. Ablation of an adjacent homolog not only caused increased outgrowth of the $P_{D}$ cell's major projection toward the ablated cell, but also reduced outgrowth on the opposite side (e.g., Figs. $3 A, B ; 4 A$ ). The summed outgrowth on one side of the major projection (sum of all three branches) is shown on the left in Figure $4 B$. Irrespective of whether the anterior or posterior homolog was deleted, whenever branches showed increased outgrowth in one direction, the amount of outgrowth of oppositely directed branches was found to be reduced, by measuring either branch length in annular units $(n=12 ; p<0.005)$ or arbor size by the number of occupied squares using the grid method ( $n=$ $6 ; p<0.0005$; see Materials and Methods). Similar results were obtained from 3-6 d after ablation (not shown). Since there was no experimentally induced change in the environment on the side away from the ablation, these results clearly show that the growth of axonal branches is not only regulated by the local environment they encounter, but also by the growth of sibling branches in distal regions.

The total outgrowth of the $P_{D}$ cell for each experimental condition is also presented in Figure $4 B$, on the right. Four days after ablation, the full extent of arborization of the $P_{D}$ cell was not significantly different from controls, as measured by the numbers of annuli innervated $(n=12 ; p>0.2$ ). As a further test of whether the total arborization of a developing $P_{D}$ cell is regulated, we ablated both neighboring homologs at $\mathrm{E} 8$ and quantitated the remaining cell's growth $5 \mathrm{~d}$ later. We observed that the number of annuli innervated by all six branches of the major projection and two minor projections was not statistically different from the controls $(n=6 ; p>0.5)$. The morphology of the branches after ablation was unusual, however, in that for the major projection each branch had a very different length, and this varied from cell to cell. The lack of symmetry under these conditions suggests that the normally symmetric profiles are due, in part, to interactions with neighboring homologs.

Eliminating the major and one minor projection of $a P_{D}$ cell causes expansion of the remaining minor projection. The results of the above experiments strongly suggest that different branches of the major projection grow at the expense of each other. In the following experiment, we further demonstrate that competition for outgrowth also exists between the major and the minor projections of the same cell.

In the first set of experiments (diagrammed in Fig. $5 A$ ), we tried to encourage a minor branch of a $P_{D}$ cell to grow, in order to determine if it could generate an arbor as large as that of a normal major projection. To achieve this, two $\mathrm{P}_{\mathrm{D}}$ cells in ganglion $N$ were ablated at $\mathrm{E} 8$ and the roots of each of the two posterior ganglia $(N+1$ and $N+2)$ were cut on one side (Fig. $5 A$ ). The two $\mathrm{P}_{\mathrm{D}}$ neurons in ganglion $N+1$ were stained $3-4 \mathrm{~d}$ later to examine their morphologies. The contralateral $P_{D}$ cell in ganglion $N+1$ served as a control.

In 7 of the 23 operated embryos, the severed roots did not regenerate. As shown in Figure $6 A$, the morphology of the control $\mathrm{P}_{\mathrm{D}}$ cells resembled the diagram in Figure $5 A$, with slightly increased outgrowth of the anterior minor projection presumably due to removing inhibition by deleting the anterior cell. In contrast, on the experimental side (Fig. $6 B$ ) the minor projection in segment $N$ was found to have grown profusely, generating six 

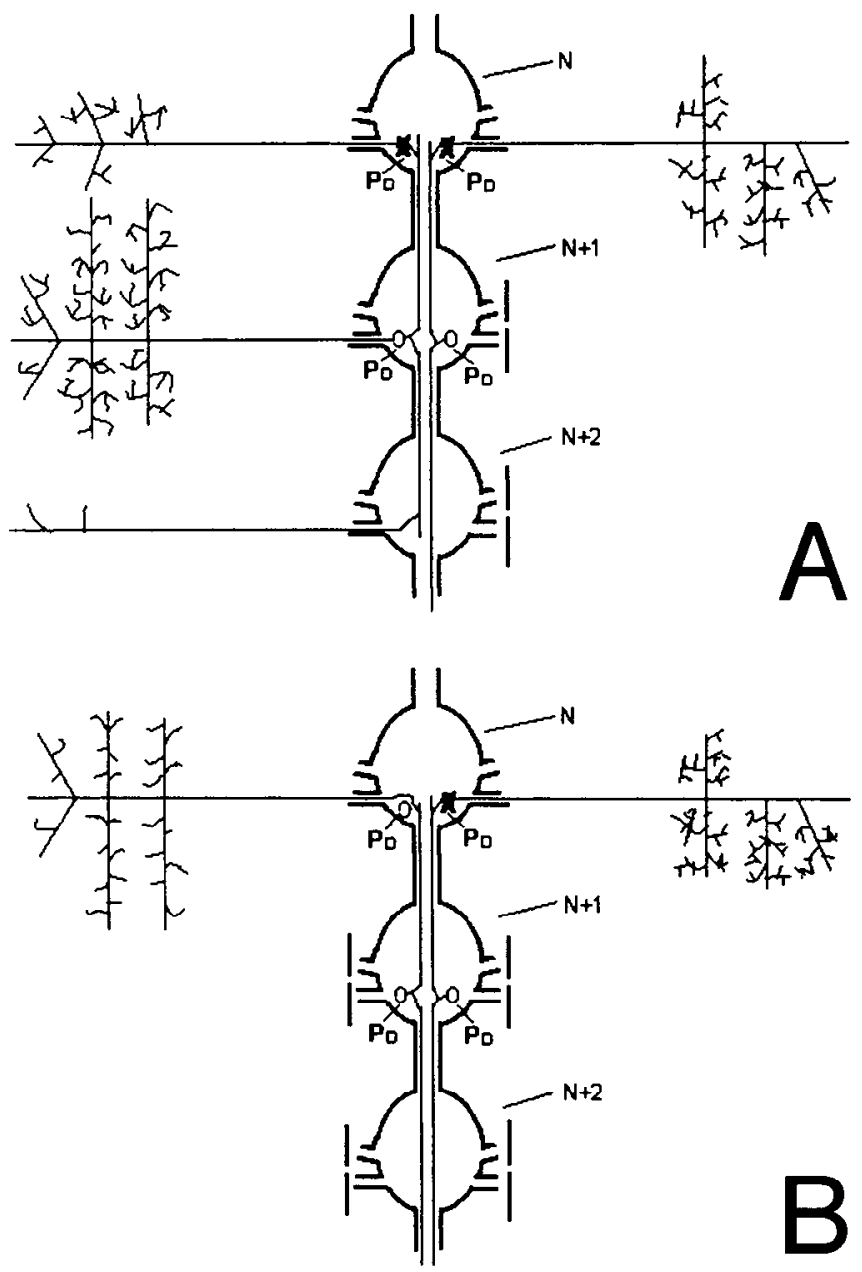

Figure 5. Diagrams of experimental manipulations for studying how major and minor projections of the same $P_{D}$ cell compete for outgrowth. $A$, To force outgrowth of a minor branch, the two $\mathrm{P}_{\mathrm{D}}$ cells in ganglion $N$ were ablated while severing the roots of the two adjacent ganglia $(N+1$ and $N+2)$ on one side. The left cell served as the control. Operations were performed at $\mathrm{E} 8$, when the projections just reach the margin of the germinal plate and begin to form first-order branches. Three to four days later, the $P_{D}$ cells in $N+1$ werc staincd with Dil to examinc their outgrowth. $B$, Diagram of a complementary experiment, in which major and posterior minor projections of both $\mathrm{P}_{\mathrm{D}}$ cells in $N+1$ were prevented from growing, but only one $\mathrm{P}_{\mathrm{D}}$ cell in ganglion $N$ was ablated. The experimental conditions are identical on the right side of both $A$ and $B$.

branches along apparently normal paths, and possessing many filopodia. The induced outgrowth of the minor projection covered $12.7 \pm 1$ annuli $(n-7)$, significantly larger than the control value of $2.8 \pm 0.3$ annuli $(n=75)(p<0.0001)$. In five cases, the arbors generated were asymmetric (Fig. 6C), with more outgrowth towards the cell's own segment $(N+1)$. This asymmetry may have been due to the homolog in ganglion $N-1$ inhibiting growth towards its segment, since such inhibition did not exist in segment $N+1$. Regardless of the shape, however, the total outgrowth of induced minor projections was significantly less than the total outgrowth of a control major projection ( $n=7 ; p<0.001)$.

In the remaining 16 preparations, the major projection of the $\mathrm{P}_{\mathrm{D}}$ cell in ganglion $N+1$ regenerated, innervating the dorsal body wall. In eight of these cases, the $P_{D}$ cells formed nearly normal terminal fields, comparable to those of their contralateral homologs. In the remaining eight embryos, however, the minor projection in segment $N$ had significantly increased outgrowth (Fig. $6 E$ ), even though the regenerated major projection in segment $N+1$ had arborized profusely. We interpret this result as evidence that the regeneration of the major projection was probably delayed, allowing the minor projection to get a "head start."

We also compared the outgrowth of a minor projection in the presence and in the absence of the local $\mathrm{P}_{\mathrm{D}}$ 's major projection. This experiment is illustrated in Figure $5 B$. The roots on both sides of ganglia $N+1$ and $N+2$ were cut at E8-9, to force growth of the remaining projection, and then only one of the $\mathrm{P}_{\mathrm{D}}$ neurons in $N$ was ablated. After $4 \mathrm{~d}$, the $\mathrm{P}_{\mathrm{D}}$ cells in ganglion $N+1$ were filled with dye. In all eight cases in which the roots did not regenerate, the minor arbors of both $\mathrm{P}_{\mathrm{D}}$ cells in ganglion $N+1$ grew considerably, showing that one branch of a cell can grow at the expense of others regardless of the presence of inhibition by another neuron. There was one important difference, however: in the presence of the Iocal $\mathrm{P}_{\mathrm{D}}$ cell (Figs. $2 \mathrm{D}, 6 \mathrm{D}$ ), the minor projection had much less higher order branching than it did that in the absence of the $P_{D}$ cell, in all eight preparations (e.g., compare Fig. $6 D$ with $B, C$ ).

\section{Interactions between adjacent homologs inhibit the formation of filopodia}

We normally observed fewer higher order branches where the major projections of adjacent $\mathrm{P}_{\mathrm{D}}$ cells overlapped (e.g., Fig. 2B). However, following the ablation of a homolog, many more highorder branches and filopodia were observed to emanate from the distal tips of first-order branches ( $n=20$; compare Fig. 7A,B). Ihe ablation of an adjacent $P_{D}$ cell also induced the formation of many more filopodia and higher order branches at the tips of the minor projections (compare Figs. $3 A, B ; 6 A$ ). Since higher order branches appear to be derived from filopodia (Wang and Macagno, 1994), we conclude that the interactions between adjacent $\mathrm{P}_{\mathrm{D}}$ neurons inhibit the formation of filopodia.

Furthermore, after elimination of the major and one minor projection, the remaining minor projection that grew in the presence of the Jocal $\mathrm{P}_{\mathrm{D}}$ cell had far fewer high-order branches than the one that grew in the absence of the local homolog $(n-8$; e.g., Figs. $2 D$, yellow branches; $6 D$ ), again indicating that the formation of filopodia were inhibited by the local $\mathrm{P}_{\mathrm{D}}$ cell. Moreover, those branches of the minor projection that grew into a region without branches of the local $P_{D}$ cell had many more high-order branches than branches that did not (e.g., Fig. 2D, red branches).

\section{Discussion}

The results presented here demonstrate that a $P_{1}$ neuron has a very significant capacity to respond to experimental intervention. Our major findings are the following: (1) the outgrowth of both major and minor projections of the $\mathrm{P}_{\mathrm{D}}$ cell increases within the territory vacated by the ablated adjacent homologs; (2) the increased growth of the branches on one side of the major projection induced by homolog ablation results in the reduced growth of branches on the other side; and (3) the elimination of the major and one minor projection of a $P_{D}$ neuron induces profuse branching in the remaining minor projection. These findings lead us to two major conclusions: first, adjacent $\mathrm{P}_{D}$ homologs inhibit each other's outgrowth in the periphery, and second, different branches of the same $P_{D}$ neuron compete with and grow at the expense of each other. 

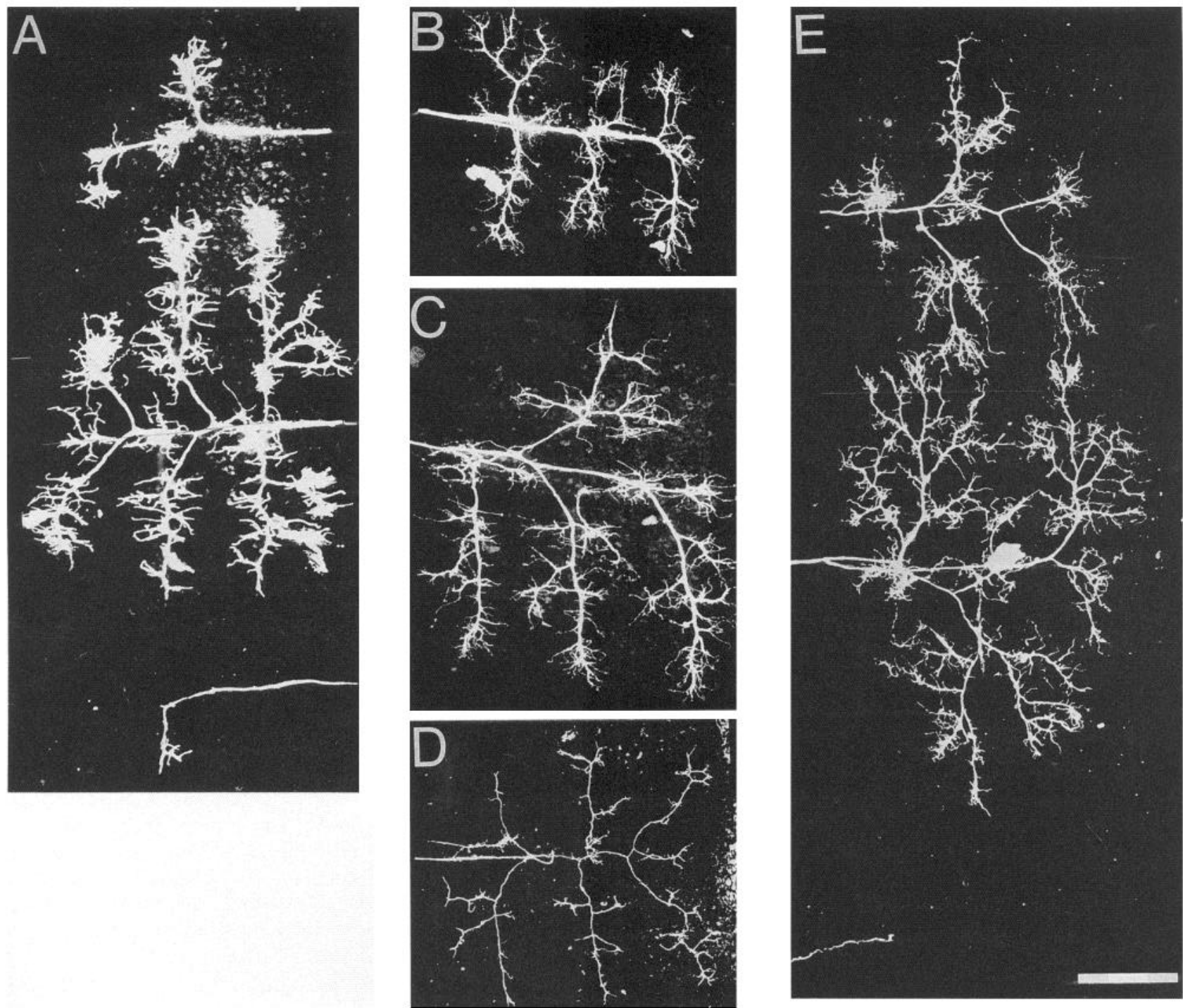

Figure 6. Major and minor projections of the same $\mathrm{P}_{\mathrm{D}}$ cell compete for outgrowth. $A, \mathrm{P}_{\mathrm{D}}$ cell corresponding to the left side of the diagram in Figure $5 A$. The minor projection in the anterior segment is only slightly larger than in unoperated animals due to removal of the local $\mathrm{P}_{\mathrm{D}}$ cell. $B$ and $C$, Minor projections of the experimental $\mathrm{P}_{\mathrm{D}}$ cells corresponding to the experiment diagrammed in Figure $5 A$, right side. These shows extensive outgrowth after the elimination of the major and one minor projection of the $\mathrm{P}_{\mathrm{D}}$ cell, sometimes forming symmetric $(B)$ and sometimes asymmetric $(C)$ arbors. $D$, Minor projection of the experimental $\mathrm{P}_{\mathrm{D}}$ cell corresponding to the experiment diagrammed in Figure $5 B$, right side. Comparing this to $B$ and $C$, one notes that the minor projection of the $\mathrm{P}_{\mathrm{D}}$ cell had fewer higher order branches in the presence of the local $\mathrm{P}_{\mathrm{D}}$ cell. $E$, Same experiment as in $B$, but the major and minor projection that were cut have regenerated. The anterior minor projection shows extensive outgrowth, suggesting that it competed favorably with the regenerated major projection (see Results). Scale bar, $100 \mu \mathrm{m}$ for $A-E$.

\section{Inhibitory interactions between homologs}

The mechanisms underlying inhibition of axonal outgrowth in this system are unknown. Studies in other systems have led to the proposals that patterns of neuronal activity (e.g., Purves, 1983; Thompson, 1983; Cline and Constantine-Paton, 1989; Shatz, 1990) or competition for trophic factors (e.g., Diamond et al., 1992) are involved in the allocation of target space. Although no data as yet directly support these ideas in the leech, we cannot rule out their contributing significantly to the refinement of synaptic connections. However, the observation of close apposition and probable touching between peripheral branches of adjacent $P_{D}$ cells suggests that some form of contact inhibition may be of primary importance in the phenomena described here. It is possible, for example, that receptors on the neurites of adjacent homologs are activated by contact to convey the signals that mediate the inhibition of filopodial extension and thus reduce the formation of higher order branches in the region where their arbors overlap.

Contact inhibition between segmental homologs, but within the CNS, has been documented for several other leech neurons (HA, AP, and AE neurons: Gao and Macagno, 1987a,b; S interneurons: McGlade-McCulloh and Muller, 1989). In each case, the longitudinal axons of adjacent homologs project toward each other within the connective nerves until they overlap, at which time they inhibit each other's further extension to the next ganglion. These stopped projections later disappear in most cases (the $\mathrm{S}$ cell is the exception). Ablation of a homolog induces the corresponding stopped longitudinal axon of the remaining homolog to renew its growth and to innervate vacated central and/ or peripheral territory. The mechanisms underlying this inhibi- 

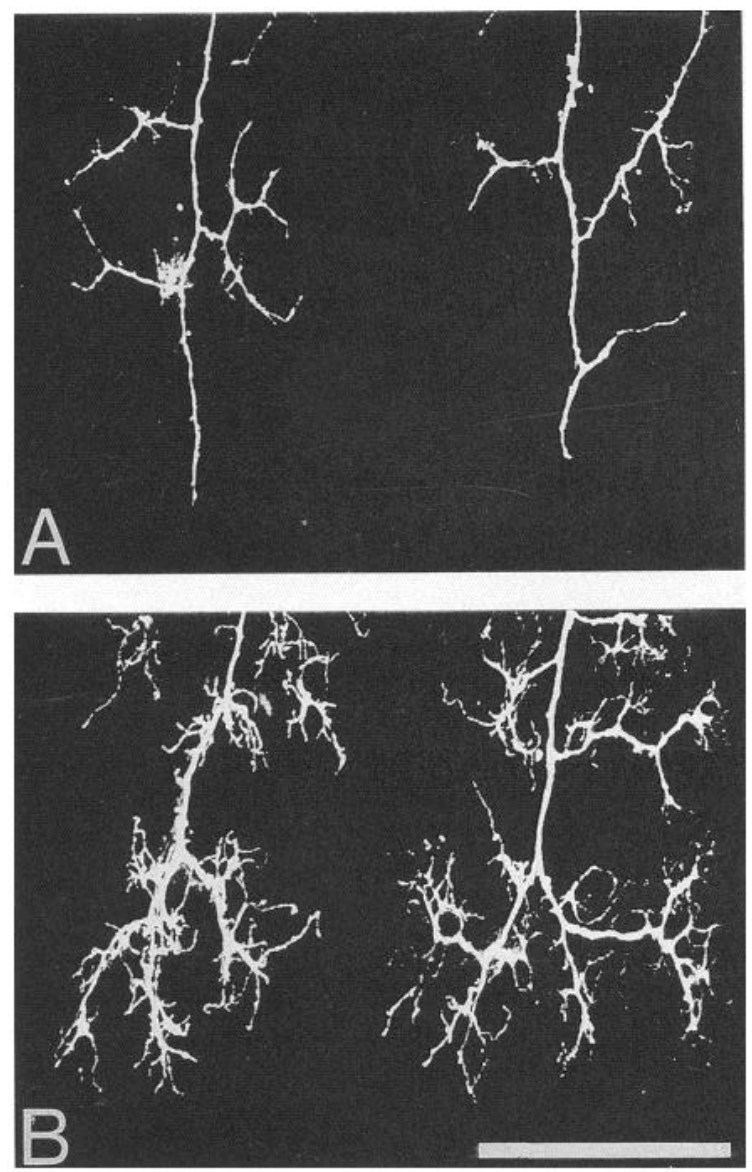

Figure 7. Inhibition between adjacent $\mathrm{P}_{\mathrm{D}}$ cells reduces the number of filopodia. A, High-power views of the distal parts of the first and second branches of a normal $P_{D}$ cell, where it overlaps with another $P_{D}$ cell. Note the paucity of filopodia. $B$, Experimental $\mathrm{P}_{\mathrm{D}}$ neuron, $4 \mathrm{~d}$ after ablation of the posterior adjacent homolog. The striking increase in the number of filopodia in the absence of the homolog suggests that neighboring projections have an inhibitory influence on filopodial extension. Scale bar, $100 \mu \mathrm{m}$.

tion and the subsequent regrowth are not known, but in the cases of the S and AP cells (McGlade-McCulloh and Muller, 1989; Wolszon et al., 1994a), gap junctions are known to link adjacent homologs via their longitudinal axons. These gap junctions may facilitate the exchange of growth-inhibiting or growth-enhancing signals between homologs during development (Wolszon et al., 1994b).

Comparing AP or AE motor neurons to the $\mathrm{P}_{\mathrm{D}}$ sensory cells, one is immediately struck by the difference in the behavior of the longitudinal, interganglionic projections, which are extended in both cases but lost in the first and retained in the second. We do not know whether this difference in neurite behavior is due to a total lack of mutual inhibition in the case of the $\mathrm{P}_{\mathrm{D}}$ homologs or to the presence of an insufficient level of inhibition. However, since mutual inhibition is clearly present between peripheral branches, the first alternative seems unlikely. Moreover, the fact that the minor projections of a $P_{D}$ cell grow much less vigorously than its major projection could be taken as evidence that the former are partially inhibited by the projections of the neighboring homolog. A simple test of this hypothesis would be to ablate a $P_{D}$ neuron very early (E6-7), before it has a chance to affect the pattern of growth of its homologs. Unfortunately, tech- nical difficulties make it impossible for us to ablate a $P_{D}$ cell early enough and, hence, this question was not explored in these studies.

In addition to the inhibitory interaction between adjacent homologs, it has been shown, in the case of the $\mathrm{P}_{\mathrm{V}}$ neuron in the leech Haementaria ghilianii, that peripheral branches belonging to the same mechanosensory neuron avoid growing along each other, by a process called "self-avoidance" (Kramer, 1982; Kramer and Stent, 1985). Self-avoidance may also regulate the outgrowth of the $\mathrm{P}_{\mathrm{D}}$ cell in Hirudo; different branches of the same $P_{D}$ neuron do not appear to overlap at all, compared with the extensive overlap we have observed between branches of adjacent homologs. It is not known whether the same mechanisms are used by self-avoidance and mutual inhibition.

It is also worth noting that, in their study of possible interactions between adjacent $P_{\mathrm{V}}$ homologs, Kramer and Stent (1985) failed to observe mutual inhibition. Rather, they interpreted their results as evidence that branches of adjacent $\mathrm{P}_{\mathrm{V}}$ homologs facilitate each other's growth. This is in contrast to results of work with Hirudo, in which mutual inhibition occurs between adjacent embryonic $\mathrm{P}_{\mathrm{D}}$ homologs (this article) and between adjacent adult $\mathrm{T}$ or $\mathrm{N}$ neurons (Blackshaw et al., 1982). Although these conflicting findings might be explained by the fact that different species and different neurons are involved, this issue clearly needs to be investigated further.

Finally, contact inhibition may also play an important role in modulating axonal outgrowth in other systems (see Schwab et al., 1993, for a recent review). In vitro, for example, growth cones from chick central neurons collapse when they meet neurites from peripheral neurons and vice versa (Kapfhammer and Raper, 1987; Raper and Kapfhammer, 1990). Similarly, rat sympathetic neurons or chick dorsal root ganglion cells can collapse upon encountering neurites or growth cones of other neurons (Ivins and Pittman, 1989; Honig and Burden, 1993).

\section{Interactions among branches of the same neuron}

The second major finding in this report is that growing branches of the same neuron can influence each other's growth rate. We observed, a few days after the ablation of an adjacent homolog, a strongly biased outgrowth of those branches of the major projection directed towards the vacated territory, apparently at the expense of branches growing in the opposite direction. Since in these experiments the total amount of arborization of the major projection was not found to differ significantly from control values, we conclude that the overall rate of growth of the arborization of the major projection must be regulated, but individual branches can grow at different rates that can be separately influenced. Some of our data suggest that pairs of branches of the same order that have a common origin may compete directly with each other (refer to Fig. $2 C$ for an example). We plan to test this idea directly in the future, by using a laser microbeam to cut individual branches of various orders.

Our observations provide strong support for an hypothesis originally put forward by Devor and Schneider (1975) and later called "sibling neurite bias" by Smalheiser and Crain (1984), The basis for this phenomenon is thought to be that a neuronal cell body makes only a certain amount of material at a given time, forcing different branches of the same cell to compete for the limited supply for growth and/or survival (e.g., Devor and Schneider, 1975; Van Essen, 1982; Murphey and Lemere 1984; Smalheiser and Crain, 1984; Goldberg and Schacher, 1987). Such competition may play an important role in regulating ax- 
onal outgrowth and the establishment of synaptic connections. For example, in many developing nervous system, neurons initially extend many more branches into different areas than they finally retain in the target area (Schneider, 1973; Brown et al., 1976; Innocenti, 1981; Murphey and Lemere, 1984; Standfield and O'Leary, 1985; Glover and Mason, 1986; Gao and Macagno, 1987a,b; Jellies et al., 1987; Baptista and Macagno, 1988). Although it is likely that the dynamic growth and retraction of branches in these systems are, to a large extent, influenced by the local environments they encounter, it is reasonable to assume that branch extension and retraction by the same neuron are internally coordinated-extension of one branch may induce or facilitate the retraction of other branches and vice versa. In support of this idea is a recent finding that short branches of Xenopus retinal axonal arbors in the tecta of live larva extended and retracted rapidly, maintaining the same numbers of branches in each state during the $4 \mathrm{hr}$ obscrvation period (O'Rourke et al., 1994).

\section{Differential regulation of the outgrowth of the major and minor projection}

Although the $P_{D}$ cell's minor projections reach the edge of the dorsal germinal plate at about the same time as the major one, they generate much less higher order branching during development. It is possible that this difference occurs because the axons are initiated from different regions of the soma and their growth potentials are fundamentally distinct. However, our data suggest that major and minor projections may begin with approximately equal growth rates, becoming different only when they interact with their environments. Beginning at E8-E9, the growth of the minor projections is inhibited by interactions with adjacent homologs, while the major projection has little to inhibit its growth. Not until E10 do branches of the major projection encounter corresponding neurites of its neighbor and, consequently, adjust their rate and pattern of growth. Thus, the inhibition between adjacent $\mathrm{P}_{\mathrm{D}}$ cells favors the major projection having an initially greater growth rate than the minor ones. Furthermore, since different branches of the sante cell apparently grow at the expense of each other, the competition between the major and minor projection of the same $\mathrm{P}_{\mathrm{D}}$ cell tends to maintain and/or enhance the difference in their growth rates. This growth strategy, we propose, permanently biases a $P_{D}$ cell to favor the outgrowth of its major projection, and results in the strikingly different growth patterns of the major and minor projections.

The inhibition by neighboring homologs may also serve to ensure uniform innervation of territory. Without such restrictions, any branches of the $P_{D}$ cell that happen to grow slightly earlier might continue to grow at the expense of other branches, leading to random morphologies. Indeed, this irregularity in growth can often be seen in a $\mathrm{P}_{D}$ cell when the two adjacent homologs are ablated, thereby removing inhibitory influences by the flanking cells; arbors.

In conclusion, we have demonstrated here that in the leech, the formation of neuronal terminal arbors can be influenced by both neuron-neuron interactions and competition among sibling branches. These are general mechanisms that are probably present in more complex systems. The underlying molecular signals are the subject of current research efforts.

\section{References}

Baptista CA, Macagno ER (1988) Modulation of the pattern of axonal projections of a leech motor neuron by ablation or transplantation of its target. Neuron 1:949-962.
Blackshaw SE, Nicholls JG, Parnas I (1982) Expanded receptive fields of cutaneous mechanoreceptor cells after single neurone deletion in leech central nervous system. J Physiol (Lond) 326:261-268.

Browil M, Jansen J, Van Essen D (1976) Polyneuronal innervation of skeletal muscle in newborn rats and its elimination during maturation. J Physiol (Lond) 26:387-422.

Cline HT, Constantine-Paton M (1989) NMDA receptor antagonists disrupt the retinotectal topographic map. Neuron 3:413-426.

Devor M, Schneider G (1975) Neuroanatomical plasticity: the principle of conservation of total axonal arborization. In: Aspects of neural plasticity, Vol 43 (Vital-Durand F, Jeannerod M, eds), pp 191-200. Paris: INSERM Colloquia.

Diamond J, Cooper E, Turner C, Macintyre L (1976) Trophic regulation of nerve sprouting. Science 193:371-377.

Diamond J, Holmes M, Coughlin M (1992) Endogenous NGF and nerve impulses regulate the collateral sprouting of sensory axons in the skin of the adult rat. J Neurosci 12:1454-1466.

Fernandez J, Stent GS (1982) Embryonic development of the hirudinid leech Hirudo medicinalis: structure, development and segmentation of the germinal plate. J Embryol Exp Morphol 72:71-96.

Frost DO, Schneider GE (1979) Plasticity of retinofugal projections after partial lesions of the retina in newborn Syrian hamsters. J Comp Neurol 185:517 568.

Gao WQ (1989) Axonal extension and retraction by developing neurons in the leech central nervous system. Ph.D. Dissertation, Columbia University, New York.

Gao WQ, Macagno ER (1987a) Extension and retraction of axonal projections by some developing neurons in the leech depends upon the existence of neighboring homologues. I. The HA cells. J Neurobiol 18:43-59.

Gao WQ, Macagno ER (1987b) Extension and retraction of axonal projections by some developing neurons in the leech depends upon the existence of neighboring homologues. II. The AP and AE cells. J Ncurobiol 18:295-313.

Glover JC, Mason A (1986) Morphogenesis of an identified leech neuron: segmental specification of axonal outgrowth. Dev Biol 115:256260.

Goldberg DJ, Schacher SE (1987) Differential growth of the branches of a regenerating bifurcate axon is associated with differential axonal transport of organelles. Dev Biol 124:35-40.

Goodman CS, Shatz CJ (1993) Developmental mechanisms that generate precise patterns of neuronal connectivity. Cell 72 :/Neuron [Suppl] 10:77-98.

Halpern ME, Chiba A, Johansen J, Keshishian H (1991) Growth cone bchavior underlying the development of stereotypic synaptic connections in Drosophila embryos. J Neurosci 11:3227-3238.

Honig MG, Burden SM (1993) Growth cone respond in diverse ways upon encountering neurites in cultures of chick dorsal root ganglia. Dev Biol 156:454-472.

Hubel DH, Wiesel TN, LeVay S (1977) Plasticity of ocular dominance columns in the monkey striate cortex. Phil Trans R Soc Lond [Biol] 278:377-409.

Innocenti GM (1981) Growth and reshaping of axons in the establishment of visual callosal connections. Science 212:824-827.

Ivins JK, Pittman RN (1989) Growth cone-growth cone interactions in cultures of rat sympathetic ncurons. Dev Biol 135:147-157.

Jackson PC, Diamond J (1981) Regenerating axoms reclaim sensory targets from collateral nerve sprouts. Science 214:926-928.

Jellies J, Loer CM, Kristan WB Jr (1987) Morphological changes in leech Retzius neurons after target contact during embryogenesis. J Neurosci 7:2618-2629.

Kapfhammer JP, Raper JA (1987) Interactions between growth cones and neurites growing from different neural tissues in culture. J Neurosci $7: 1595-1600$.

Kramer AP (1982) The development of neuronal arborizations in the leech. In: Neuronal development: cellular approaches in invertebrates (Goodman C, Pearson K, eds), pp 882-885. Cambridge, MA: MIT Press.

Kramer AP, Kuwada JY (1983) Formation of the receptive fields of leech mechanosensory neurons during embryonic development. J Neurosci 12:2474-2486.

Kramer AP, Stent GS (1985) Development arborization of sensory neurons in the leech Haementeria ghilianii. II. Experimental induced variations in the branching pattern. $\mathrm{J}$ Neurosci 5:768-775. 
Kuwada JY (1985) Pioneering and pathfinding by an identified neuron in the embryonic leech. J Embryol Exp Morphol 86:155-167.

Kuwada JY, Kramer AP (1983) Embryonic development of the leech nervous system: primary axon outgrowth of identified neurons. $J$ Neurosci 10:2098-2111.

Landmesser LT, Dahm L, Tang J, Rutishauser U (1990) Polysialic acid as a regulator of intramuscular nerve branching during embryonic development. Neuron 4:655-667.

Lnenicka GA, Murphey RK (1989) The refinement of invertebrate synapses during development. J Neurobiol 20:339-355.

Lumsden AGS, Davies AM (1986) Chemotropic effect of specific target epithelium in the developing mammalian nervous system. Nature 323:538-539.

McGlade-McCulloh M, Muller KJ (1989) Developing axons continue to grow at their tip after synapsing with their appropriate target. Neuron 2:1063-1068.

Murphey RK, Lemere CA (1984) Competition controls the growth of an identified axonal arborization. Science 224:1352-1355.

Myers PZ, Bastiani MJ (1993) Growth cone dynamics during the migration of an identified commissural growth cone. J Neurosci 13:127143.

Nicholls JG, Baylor DA (1968) Specific modalities and receptive fields of sensory neurons in CNS of the leech. J Neurophysiol 31:740-756.

O'Rourke NA. Cline HT, Fraser SE (1994) Rapid remodeling of retinal arbors in the tectum with and without blockade of synaptic transmission. Neuron 12:921 934.

Purves D (1983) Modulation of neuronal competition by postsynaptic geometry in autonomic ganglia. Trends Neurosci 6:10-16.

Raper JA, Kapfhammer JP (1990) The enrichment of a neuronal growth cone collapsing activity from embryonic chick brain. Neuron $4: 21-29$.

Schmidt JT, Cicerone CM, Easter SS (1978) Expansion of the half retinal projection to the tectum in goldfish: an electrophysiological and anatomical study. J Comp Neurol 177:257-278.
Schneider G (1973) Early lesions of superior colliculus: factors affecting the formation of abnormal retinal projections. Brain Behav Evol 8:73-109.

Schwab ME, Kapfhammer JP, Bandtlow CE (1993) Inhibitors of neurite growth. Annu Rev Neurosci 16:565-595.

Shatz CJ (1990) Impulse activity and the patterning of connections during CNS development. Neuron 5:745-756.

Smalheiser NR, Crain SM (1984) The possible role of "sibling neurite bias" in the coordination of neurite extension, branching, and survival. J Neurobiol 15:517-529.

Stanfield BB, O'leary DDM (1985) The transient corticospinal projection from the occipital cortex during the postnatal development of the rat. J Comp Neurol 238:236-248.

Thompson WJ (1983) Synapse elimination in neonatal rat muscle is sensitive to pattern of muscle use. Nature 336:775-778.

Van Essen D (1982) Neuromuscular synapse elimination. In: Neuronal development (Spitzer N, ed), pp 333-376. New York: Plenum.

Walter J, Henke-Fahle S, Bonhoeffer F (1987) Avoidance of posterior tectal membranes by temporal retinal axons. Development 101:909913

Wang II, Macagno ER (1994) Time-lapse study of the formation of the peripheral terminal fields of pressure sensory neurons in the leech. Soc Neurosci Abstr 20:658.

Wenning A (1987) Salt and water regulation in Macrobdella decorata (Hirudinea: Gnathobdelliformes) under osmotic stress. J Exp Biol $131: 337-349$

Westerfield M, McMurray JV, Eisen JS (1986) Identified motoneurons and their innervation of axial muscles in the zebrafish. J Neurosci 6:2267-2277

Wolszon LR, Gao WQ, Passani MB, Macagno ER (1994a) Growth cone "collapse" in vivo: are inhibitory interactions mediated by gap junctions? J Neurosci 14:999-1010.

Wolszon LR, Rehder V, Kater SB, Macagno ER (1994b) Calcium wave fronts that cross gap junctions may signal neuronal death during development. J Neurosci 14:3437-3448. 